\title{
Effect of Biofertilizers on the Integrated Culture of Genetically Improved Farmed Tilapia and Green Beans in Aquaponics
}

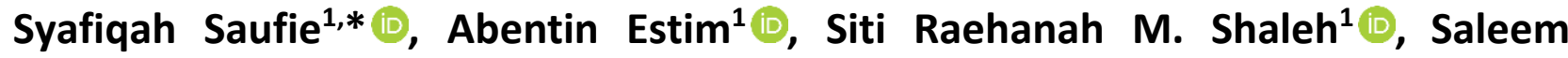 \\ Mustafa $^{1}$
}

${ }^{1}$ Universiti Malaysia Sabah, Jalan UMS, Borneo Marine Research Institute, 88450 Kota Kinabalu, Sabah, Malaysia.

\section{How to cite}

Saufie, S., Estim, A., M.Shaleh, S.R., Mustafa, S., (2022). Effect of Biofertilizers on the Integrated Culture of Genetically Improved Farmed Tilapia and Green Beans in Aquaponics, 22(3), AQUAST729. http://doi.org/10.4194/AQUAST729

\section{Article History}

Received 31 July 2021

Accepted 14 January 2022

First Online 21 January 2022

\section{Corresponding Author}

Tel.: +088320000

E-mail: syafiqahsaufie@gmail.com

\section{Keywords}

Integrated aquculture

Nutrient dynamics

Water quality

Production efficiency

System modulation

Ecological footprint

\begin{abstract}
This study was designed to determine the effect of commercial biofertilizers, namely chitosan, Bacillus spp. and Effective Microorganism formulation on the production efficiency of Genetically Improved Farmed Tilapia (Oreochromis niloticus) and green bean (Phaseolus vulgaris) in an aquaponic system. The intended purpose was to examine if the production of the two integrated species can be optimized by costeffective methods consistent with the concept of circular economy. While the biofertilizers performed water quality remediation as seen from the dynamics of turnover of ammonia $\left(\mathrm{NH}_{3}\right)$, nitrite $\left(\mathrm{NH}_{2}\right)$, nitrate $\left(\mathrm{NO}_{3}\right)$ and phosphate $\left(\mathrm{PO}_{4}\right)$ but produced no significant impact on growth of the fish, and the green bean could not attain the fruiting stage. Green beans that generally produce white-purplish flowers which transform into pods dropped off after one week on the plant. The water quality parameters: dissolved oxygen (5.54 to $6.12 \mathrm{mg} / \mathrm{L}$ ), $\mathrm{pH}(6.9$ to 7.0 ) and water temperature 26.7 to $27.8^{\circ} \mathrm{C}$ were in the suitable range but evidently the green bean faced deficiency of nutrients that are needed for fruiting. The nutritional management requires further investigations since the green bean pods are a rich source of human food, and maximum benefits from aquaponics can be derived through their production and faster growth of the fish. The trend of fish growth suggests that the biofertilizers will result in significant growth advantage if the treatment is carried out over a longer faming period.
\end{abstract}

\section{Introduction}

Aquaponic system combines aquaculture and hydroponics in a closed water recirculating system. The only fed species is a selected fish or invertebrate of aquaculture importance, while the other species in the system are extractors of inorganic and organic matter from the metabolic waste although they can also serve as human food. Operation of aquaponics is based on the principles of circular economy whereby it reduces resource inputs and recycles waste, and thus minimizes the ecological footprint of food production which contributes to the creation of environmentally friendly aquaculture system because by-products from fish are absorbed by plants, and beneficial microorganisms in the aquaponic system convert harmful nitrogen into a form that is assimilated into plant biomass.

Nitrogen is a vital nutrient generated in the water by metabolic processes of the fed species in addition to decomposition of uneaten feed particles. It undergoes a series of transformations, eventually yielding the nitrate that is used by the plant as a key nutrient for its biomass production. Besides, the other macro- and micronutrients are also released into the system and support the growth and well-being of the animal and plant species. Products of nitrogen are required for growth of 
the leaves, phosphorus is crucial for the root development and nutrient absorption from water while potassium is a key nutrient required to develop strong and rigid stems for water and nutrient transport, enzyme activation as well as promoting the flowering and fruiting process in the plant (Wang et al., 2013). Micronutrients that are needed only in small amounts could be in the water supply, and not necessarily require supplementation in the feed. The quantitative requirement of nutrients in aquaponic systems is a subject matter of on-going research investigations (Bittsanszky et al., 2016; Yang and Kim, 2020). There is no fixed amount that can be considered as a universal standard because of the different combinations of species used and their stocking densities. While the optimum diet for the fish can be decided by its known nutritional needs, the plants depend on what comes from the fish-holding tank. Plants will obviously thrive when there is no nutrient deficiency in the water (Endut et al., 2010; Trang and Brix, 2014). There are cases where vegetables cultivated in aquaponics face deficiencies of certain nutrients, depending on the specific requirements of the plants (Roosta and Hamidpour, 2011; Kazosi et al., 2019; Yang and Kim, 2020).

Optimizing production in aquaponics requires scientific data on the qualitative and quantitative nutritional needs of all the species and the impact of nutrients generated by metabolic activity of fish on the nitrification process carried out by the bacteria. In this context, use of biofertilizers is a better option to influence all the species directly or indirectly and support an efficient biodynamics because of their various attributes such as cost-effectiveness, environmental compatibility, and ability to give positive impact to aquatic animal and plant stocked in the system besides remediation of water quality (Ramasamy et al., 2020). These are the principal factors in successful output of the aquaponic systems and optimizing the biomass production of fish as well as plants. Biofertilizers can be produced from a suitable organic matter or formulated to contain beneficial microorganism. A combination of the two has been seen to improve plant growth (Atieno et al., 2020; Sun et al., 2020; Zhang et al., 2020) by supplying nutrients to the plant and boosting their efficiency to extract the specific types of nutrients needed for growth (Umesha et al., 2018). Multiple ways in which the biofertilizers improve the biomass gain and stamina of plants have been explained earlier (Javaid, 2011; Javaid and Bajwa, 2011; Malusa and Vassilev, 2014; Cerozi and Fitzsimmons, 2016; Menendez and Garcia-Fraile, 2017; Nikitin et al., 2018).

In this study, three different biofertilizers were used, chitosan (A), Bacillus spp. (B) and Effective Microorganism mixture (C) in the aquaponic system using Genetically Modified Farmed Tilapia (Oreochromis niloticus), or in short, GIFT, and green bean (Phaseolus vulgaris).

\section{Materials and Methods}

\section{Experimental Aquaponic System Design and Operation}

The experiment was carried out in Integrated Multi-trophic Aquaculture experimental area in an open space. The aquaponic facility was covered with a transparent canvas roofing to prevent direct sunlight and rain and was equipped with an aeration system. Water was supplied from the storage tanks installed in a shaded area. The experiment was conducted under natural environmental conditions. Three types of biofertilizers were used: Chitosan (A), Bacillus spp. (B) and Effective Microorganisms (C). A control set (without any of these biofertilizers) was run simultaneously. Each system comprised a $750 \mathrm{~L}$ fish tank, $25 \mathrm{~L}$ of filter tank filled with gravel and sponges for easy solid waste removal and providing substrate for nitrifying bacteria, and two connected hydroponic tanks for plant (green bean) as shown in Figure 1. Each aquaponic system was treated as an individual unit and the treatments were done in triplicate. Fish inside the tank were protected from attacks of predatory birds by placing a green cover (Figure 2 b). The aquaponic system designed for this study was media-filled type where gravel was placed in the hydroponic tank that served as a holding space for the plant in addition to supplementing the biological filtration carried out by the nitrifying bacteria. There was no water renewal since the system was recirculating type except for replacement of the evaporated water to maintain the operational volume. A submersible water pump installed in each of the fish tanks helped in lifting the water up to the level from where it could drain into the filter tank and move further into the two hydroponic media-filled sub-systems before returning to the fish tank (Figure 3).

\section{Biofertilizers Preparation}

Biofertilizer for Treatment-A was in the form of chitosan that comprised $5 \mathrm{ml}$ of commercial grade product that goes with the trade name 'Kitosan' manufactured by Dasatim Pvt. Ltd. It was diluted in 100 $\mathrm{mL}$ of water for use in the aquaponic system of $1000 \mathrm{~L}$ capacity. Treatment-B (Bacillus spp.) was also a commercial grade product available as Pondplus and its amount used was $1 \mathrm{~g}$ of the product/1000 L. This dosage is based on the instructions provided by the manufacturer.

Treatment-C comprised a mixture of Effective Microorganisms (EM) prepared by mixing the concentrated $5 \mathrm{~mL}$ EM solution in sugarcane molasses and chlorine-free tap water in the ratio of 1:1:20 (v/v). This mixture was transferred to a plastic container that was tightly capped and stored at room temperature for incubation over a period of 20 days to facilitate the fermentation process (Nikitin et al., 2018). The capped bottle was needed to be opened once every two days to release the gas trapped in the container. The EM 


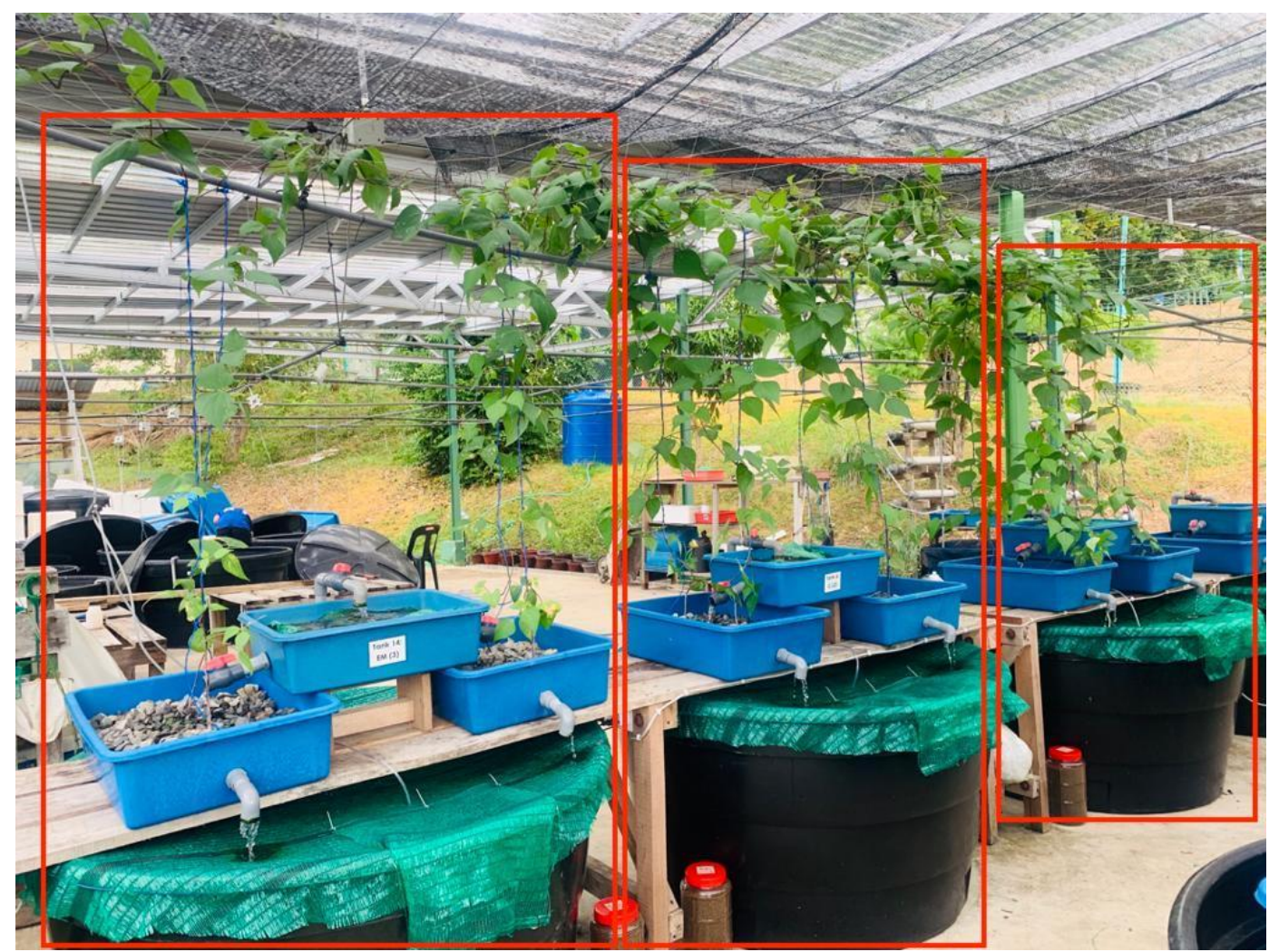

Figure 1. Individual units of aquaponic system (in red boxes) served as triplicates for each of the treatments.

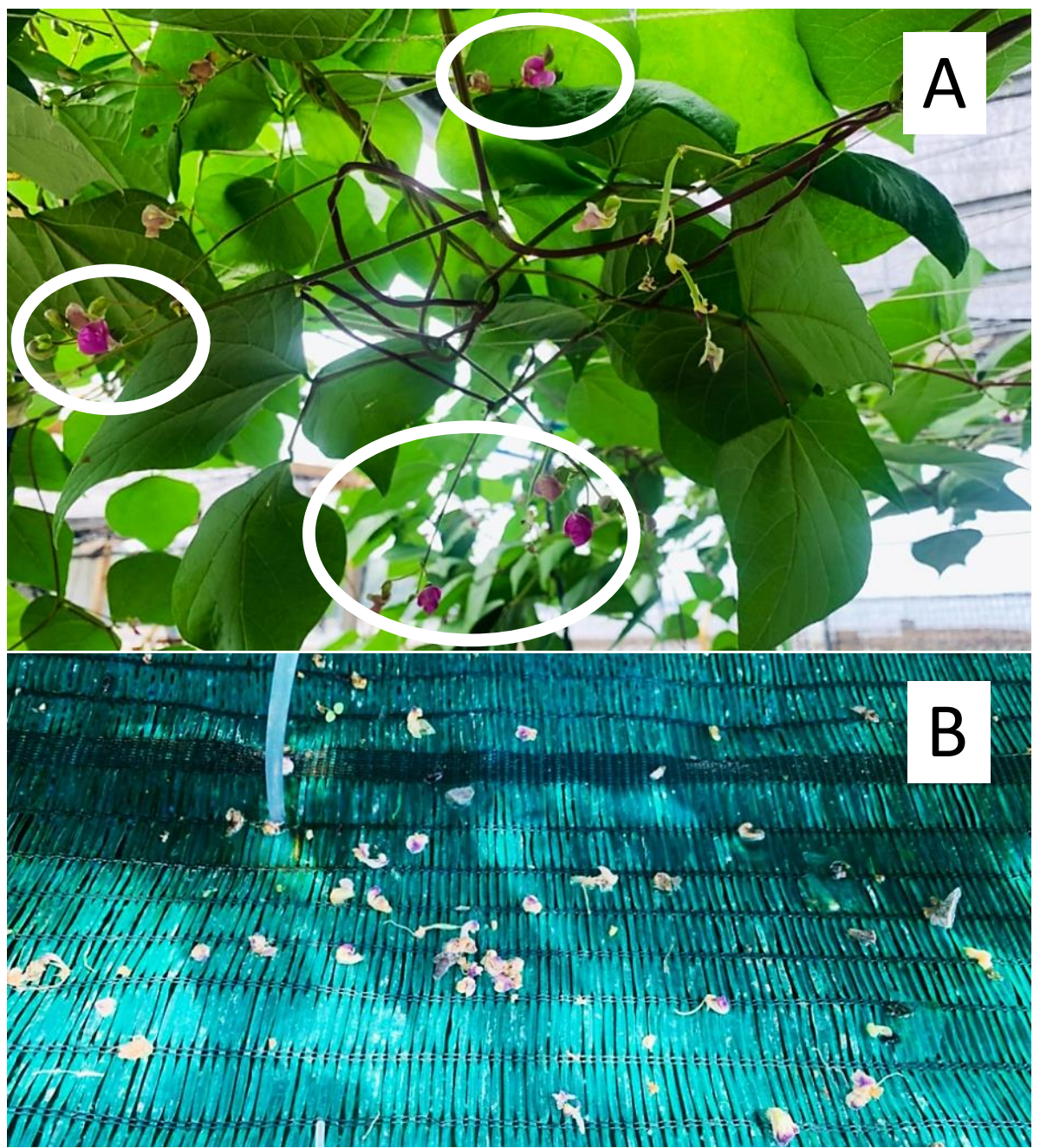

Figure 2. a. White-purplish flowers of green bean (in white circles). b. Flowers that dropped off before becoming pods. 


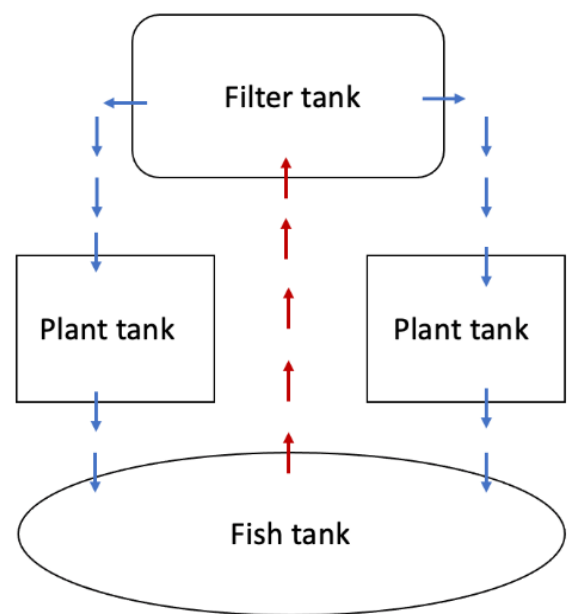

$\longrightarrow$ Water lifted-up from fish tank to filter tank

$\longrightarrow$ Water goes downward from filter tank to plant tank and back to fish tank

Figure 3. Schematic diagram of the aquaponic system designed for this study. Individual units of the aquaponic system (in red boxes) served as triplicates for each of the treatments.

solution was ready for use when it produced a pungent smell. The EM solution consisted of naturally occurring beneficial microorganisms such as lactic acid (Lactobacillus casei), photosynthetic bacteria (Rhodopseudomonas palustris) and yeast (Saccharomyces cerevisiae). This diluted EM was added to the hydroponic section of the facility. A control set was run, obviously without any of these biofertilizer treatments but otherwise under similar conditions. Each of these biofertilizers was applied once a week.

\section{Data Collection of Target Species (GIFT and Green Bean)}

Thirty GIFT juveniles of the same cohort with an average body weight of $23.24 \mathrm{~g} \pm 0.53$ were placed randomly in the triplicate experimental sets. The fish were acclimatized for two weeks before the commencement of the trial. The feed used in this study was commercial tilapia starter pellet available in the market from Leong Hup Mill Malaysia Pvt. Ltd. It is composed of $34 \%$ protein, $5 \%$ lipid and $12 \%$ moisture. Observations on the fish condition were made on a fortnightly basis over a period of 3 months which covered the life cycle of the green bean. Parameters considered were average body weight gain (g), total weight gain (g), specific growth rate (SGR), daily growth rate (DGR), survival rate (\%) and feed conversion ratio (FCR).

The following formulas were used to analyse the data obtained:

$$
\begin{gathered}
\text { Body weight gain }(B W G)=W_{2}-W_{1} \\
\text { Specific growthrate }(S G R)=\left(\frac{\ln W_{2}-\ln W_{1}}{T_{1}}\right) \times 100
\end{gathered}
$$

Survival rate $(S R)=\left(\frac{\text { number of } \text { fish at the end of experiment }}{\text { number of fish in the beginning }}\right) \times 100$

$$
\begin{gathered}
\text { Feed conversion ratio }(F C R)=\frac{\text { total weight of dry feed given }(g)}{\text { total weight gain of fish }(g)} \\
\text { Daily growth rate }(D G R)=\frac{\left(W_{2}-W_{1}\right)}{T_{1}}
\end{gathered}
$$

Where:

$\mathrm{W}_{1}$ - Initial body weight $(\mathrm{g}), \mathrm{W}_{2}$ - final weight gain (g), $\mathrm{T}_{1}$ - duration of culture period (days)

As for the measurement of growth performance of green bean, data was collected on biomass gain $(\mathrm{g})$, weight per pod $(\mathrm{g})$, number of pods produced $(\mathrm{cm})$, length of pod $(\mathrm{cm})$ and length of root $(\mathrm{cm})$. The germination process was done in the soil before transplanting to the aquaponic system. After 7 days, the seed were observed to grow to become a plantlet, and the plant grown to a height of around $5-7 \mathrm{~cm}$ was ready to be placed in the hydroponic tank. The first 30 to 45 days was the development phase for the leaves. It was necessary to provide support as the branches and stems begin to grow with leaves and form twisting vine. This is followed by the flowering stage that produces pods under normal circumstances. The plant stocking density in this study followed closely with previous study done by Saufie et al. (2020).

\section{Data Collection of Water Quality and Nutrient Dynamic Analysis}

Water samples were collected from each fish tank to determine the concentrations of ammonia, nitrite, nitrate, and phosphate. Water sampling were done at 8 am and the samples were transferred to the laboratory and kept in a refrigerator until analysis. Ammonia concentration was determined using Hach Ammonia Low-Range Standard Method 10023. Nitrite was determined using the Hach Low-range Standard Method 8192. Nitrate was measured by the help of Hach Low- 
range Standard Method 8093. Phosphate was determined by the Hach Standard Method 8048. Nutrient concentrations were analysed spectrophotometrically using the photometer model UNICO 2100. Measurements of dissolved oxygen (DO), $\mathrm{pH}$ and temperature $\left({ }^{\circ} \mathrm{C}\right)$ were carried out using the $\mathrm{YSI}$ multi probe (YSI 550A model). These measurements were done once every two days in the morning at 8.00 AM.

\section{Statistical Analysis}

Data obtained from this study was analysed with SPSS (Statistical Package for Social Sciences) ver. 21 (SPSS Inc. USA) and Microsoft Excel 2015 for data recording. Results obtained were expressed as mean \pm standard error (SE) and significance of difference was determined by one-way ANOVA (analysis of variance) to express the effect of application of different types of biofertilizers on growth of GIFT, green beans, and the dynamic changes in the water quality. Comparisons were made with Shapiro-wilk test and the difference between the mean values was evaluated using Tukey HSD Test.

\section{Results}

\section{Growth Performance of GIFT}

There was no significant difference $(P<0.05)$ in the growth performance of GIFT in terms of SGR, DGR, SR, FCR, AWG and TWG between the treatments over the period of observations but a trend was evident that indicated the level of influence of biofertilizers (Table 1).

\section{Growth Performance of Green Bean}

Growth of the green bean in each of the treatment ( $A, B$ and $C$ ) in early stage was remarkable. From the observation, the plant maintained a steady pattern of growth following its transfer to the aquaponic system. The stems and leaves continued to grow in a healthy condition in the first 45 days of the experiment. The whitish purple flowers appeared and unlike under normal conditions whence they give rise to green pods, these flowers dropped off and none attained the fruiting stage (Figure 2). At the end of the experimental period, not a single green bean pod was produced although the maintenance operations were extended for another 2 weeks. Because green bean pods did not develop in this experimental trial, there is no data on their biomass production.

\section{Water Quality Analysis}

There was no significant difference $(\mathrm{P}<0.05)$ in $\mathrm{pH}$, temperature, and dissolved oxygen of the water that were monitored on a daily basis (Table 2).

Quantitative profiles of ammonia $\left(\mathrm{NH}_{3}\right)$, nitrite $\left(\mathrm{NH}_{2}\right)$, nitrate $\left(\mathrm{NO}_{3}\right)$ and phosphate $\left(\mathrm{PO}_{4}\right)$ in the three treatments are shown in Figure 4 . There was no significant difference in their concentrations $(P<0.05)$ at any one time. Blue line represents the control set which has the highest concentration of $\mathrm{NH}_{3}, \mathrm{NH}_{2}, \mathrm{NO}_{3}$ and $\mathrm{PO}_{4}$ among all of the treatments. Regarding the concentration of $\mathrm{NH}_{3}$, a change was noticed after the $1^{\text {st }}$ week of the experiment, with the highest value seen in the Control treatment $(1.08 \mathrm{mg} / \mathrm{L})$, followed by Treatment-B (0.8 mg/L) and Treatment-A $(0.7 \mathrm{mg} / \mathrm{L})$ and the lowest in Treatment-C $(0.5 \mathrm{mg} / \mathrm{L})$. However, after week 3 , the fluctuations were different for each treatment. On the last phase of the experimental period, Treatment- $B(0.3 \mathrm{mg} / \mathrm{L})$ treatment showed the lowest concentration of $\mathrm{NH}_{3}$ followed by Treatment-A $(0.4$ $\mathrm{mg} / \mathrm{L})$, while Treatment- $\mathrm{C}$ and the Control exhibited approximately the same concentration $(0.6 \mathrm{mg} / \mathrm{L})$.

Initial concentrations of $\mathrm{NH}_{2}$ were almost similar in all the treatments. From its value of $5.0 \mathrm{mg} / \mathrm{L}$ in week 5 , the $\mathrm{NH}_{2}$ gradually declined towards the end of the experiment but the values still remained higher compared to those in the other treatments. Fluctuations in the concentration can be seen in the treatments of Treatment-B and Treatment-C. While in Treatment-B, the concentration increased in a small amount and

Table 1. Growth performance of GIFT (SGR, DGR, SR, FCR, AWG AND TWG) in the various treatments

\begin{tabular}{|c|c|c|c|c|}
\hline Parameters & Control & A & B & C \\
\hline Specific growth rate ${ }^{1}$, (SGR) & $2.33 \pm 0.04$ & $2.37 \pm 0.03$ & $2.41 \pm 0.08$ & $2.49 \pm 0.13$ \\
\hline Daily growth rate ${ }^{1}$ (DGR) & $2.19 \pm 0.08$ & $2.22 \pm 0.1$ & $2.42 \pm 0.22$ & $2.51 \pm 0.27$ \\
\hline Survival rate (SR), \% & $73.3 \pm 0.1$ & $72.2 \pm 4.8$ & $71.1 \pm 4.8$ & $71.1 \pm 5.8$ \\
\hline Feed conversion ratio ${ }^{1}$ (FCR) & $1.28 \pm 0.05$ & $1.27 \pm 0.05$ & $1.25 \pm 0.03$ & $1.28 \pm 0.05$ \\
\hline Average weight gain ${ }^{1}$ (AWG), g & $210.05 \pm 7.8$ & $212.8 \pm 8.1$ & $221.4 \pm 10.3$ & $215.7 \pm 9.2$ \\
\hline Total weight gain ${ }^{1}$ (TWG), g & $4621.02 \pm 172.7$ & $4591 \pm 186.3$ & $4694.8 \pm 102.9$ & $4571 \pm 207$ \\
\hline
\end{tabular}

Table 2. Dissolved oxygen (DO), $\mathrm{pH}$ and temperature $\left({ }^{\circ} \mathrm{C}\right)$ for Control and $\mathrm{A}, \mathrm{B}$ and $\mathrm{C}$ treatments

\begin{tabular}{lcccc}
\hline Parameter & Control & A & B & $C$ \\
\hline DO $(\mathrm{mg} / \mathrm{L})$ & $5.54 \pm 0.2$ & $5.58 \pm 0.21$ & $6.12 \pm 0.56$ & $5.6 \pm 0.19$ \\
$\mathrm{pH}$ & $6.86 \pm 0.14$ & $6.9 \pm 0.13$ & $6.9 \pm 0.13$ & $7.0 \pm 0.13$ \\
Temp $\left({ }^{\circ} \mathrm{C}\right)$ & $27.6 \pm 0.14$ & $27.7 \pm 0.15$ & $27.8 \pm 0.16$ & $27.6 \pm 0.13$ \\
\hline
\end{tabular}


eventually decreased after week 9. By the end of the experiment, the lowest concentration of $\mathrm{NH}_{2}$ was noticed in Treatment-A $(3 \mathrm{mg} / \mathrm{L})$, followed by Treatment-C (3.5 mg/L), Treatment-B $(3.70 \mathrm{mg} / \mathrm{L})$ and Control $(4.5 \mathrm{mg} / \mathrm{L})$.

The concentration of $\mathrm{NO}_{3}$ was usually high due to it being the final product of the conversion of $\mathrm{NH}_{3}$ and $\mathrm{NH}_{2}$. It varied from 5 to $27 \mathrm{mg} / \mathrm{L}$. The graph showed an increasing trend in all of the treatments except Treatment- $\mathrm{B}$ where the lowest concentration of $\mathrm{NO}_{3}$ at the end of experiment was $17 \mathrm{mg} / \mathrm{L}$, followed by Treatment-C (22.1 mg/L) and Treatment-A ( $25 \mathrm{mg} / \mathrm{L})$. It was maximum in the Control set $(27 \mathrm{mg} / \mathrm{L})$. The initial concentrations of $\mathrm{PO}_{4}$ were high in all of the treatments as compared to the other nutrients, but values declined gradually until week 7 when the decrease was sharp, reaching the lowest concentration $(1.8 \mathrm{mg} / \mathrm{L})$. Finally, at the end of the experiment (week 13), Treatment-B (2.6 $\mathrm{mg} / \mathrm{L})$ exhibited the lowest concentration of $\mathrm{PO}_{4}$ followed by Treatment-A $(3.0 \mathrm{mg} / \mathrm{L})$, Treatment-C (3.2 $\mathrm{mg} / \mathrm{L})$, and Control (3.8 mg/L).
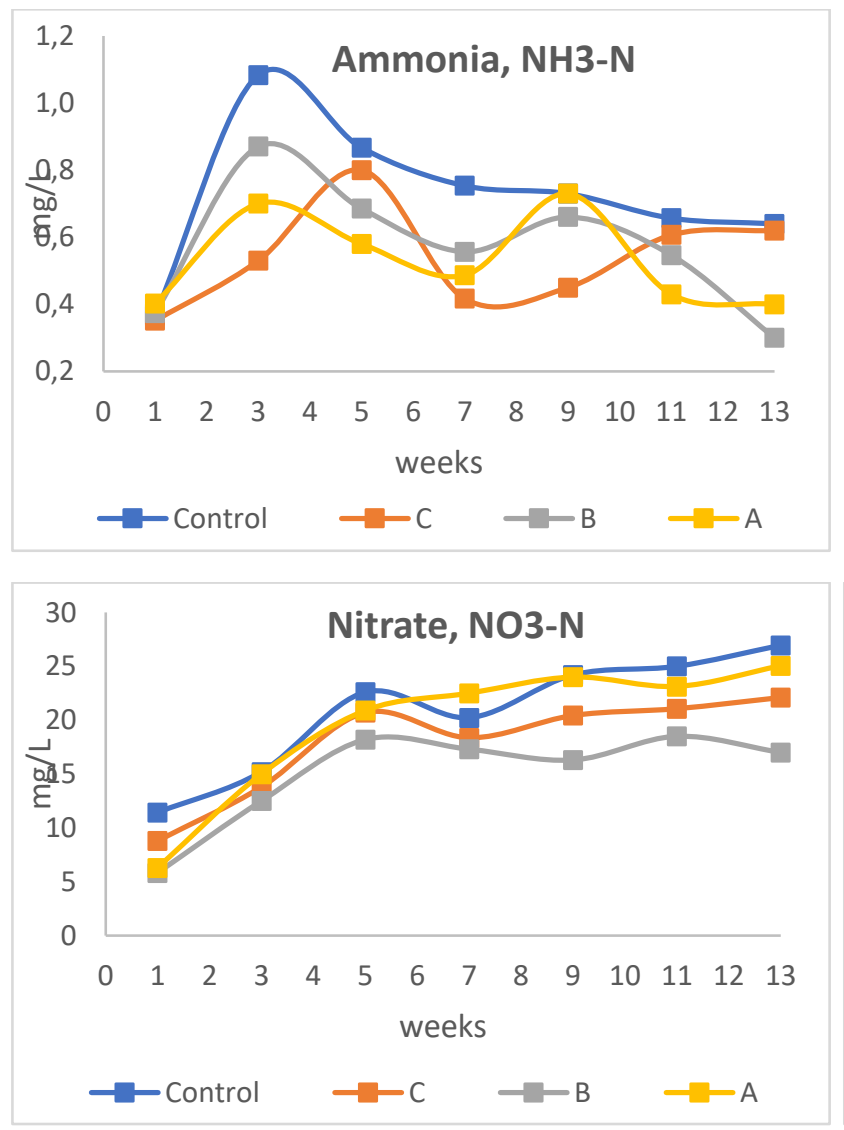

\section{Outdoor Temperature (Open Space Area)}

Data on the surrounding temperature $\left({ }^{\circ} \mathrm{C}\right)$ in Kota Kinabalu, Sabah, during the experimental period was obtained from the Department of Meteorology (Table 3). Temperature varied in the range of 27 to $36^{\circ} \mathrm{C}$ which is considered high. This could have negatively affected the growth of the green beans.

\section{Discussion}

The result indicated that fish growth performance was not affected by the presence of plants and the selected biofertilizers in the aquaponics system. There was no significant difference $(P<0.05)$ in any of the growth parameters of the fish. The results are consistent with an earlier study by Estim et al. (2019) who suggested that the presence of plant integrated in the hydroponic sub-system did not influence the fish growth.
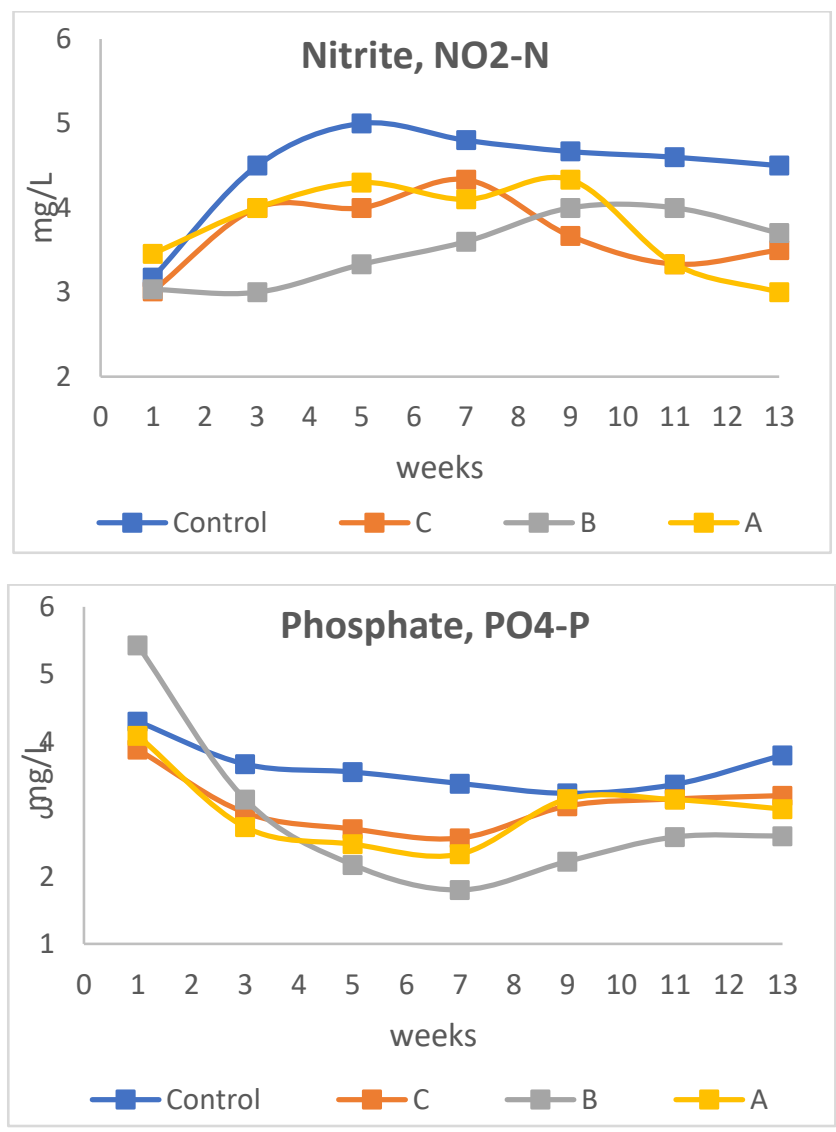

Figure 4. Concentrations of ammonia $\left(\mathrm{NH}_{3}-\mathrm{N}\right)$, nitrite $\left(\mathrm{NO}_{2}-\mathrm{N}\right)$, nitrate $\left(\mathrm{NO}_{3}-\mathrm{N}\right)$ and phosphate $\left(\mathrm{PO}_{4}-\mathrm{P}\right)$ in Treatments $\mathrm{A}, \mathrm{B}$ and $\mathrm{C}$, and the Control set.

Table 3 Environmental temperature $\left({ }^{\circ} \mathrm{C}\right)$ data in Kota Kinabalu during experiment 1 and 2

\begin{tabular}{lccccccccc}
\hline & Temp $\left({ }^{\circ} \mathrm{C}\right)$ & \multicolumn{3}{c}{ Exp. 1 (Jan - April 2018) } & \multicolumn{3}{c}{ Exp. 2 (March - June 2019) } \\
\hline Environmental Temperature $\left({ }^{\circ} \mathrm{C}\right)$ & & Jan & Feb & Mac & April & March & April & May & June \\
& Lowest & 30 & 27 & 29 & 30 & 32 & 34 & 33 & 30 \\
& Highest & 32 & 32 & 31 & 34 & 34 & 36 & 35 & 33 \\
\hline
\end{tabular}


Treatment-A produced no significant growth advantage in the fish unlike the increase in daily weight gain observed in Nile tilapia by Wang and Li (2011). A review of published data also suggests no appreciable growth-promoting effect of chitosan even though the amount of this product in the diet was higher in the range of $5-20 \mathrm{~g} / \mathrm{kg}$ (Maqsood et al., 2010; Chen et al., 2014; Abd El-Naby et al., 2019). Lack of significant effect on growth of the fish s could be due to poor uptake of this product in GIFT. The EM also did not produce any noticeable influence on tilapia growth (Treatment-C) but it is still suggested by several authors, notably Thiam et al. (2015), as an additive in tilapia diets for improved feed efficiency and health of the fish over extended periods of farming. This is supported by Omar et al. (2017) who highlighted the probiotic role of EM in the physiological condition of tilapia and its production efficiency in culture systems. The method of providing biofertilizers can make a difference on a comparative basis. Adding directly into the water or delivering through feed would certainly matter in the product's uptake by the fish. Although the quantitative differences have not been investigated but incorporation in the feed will be subject to digestive processes and absorption of the hydrolysed fractions. The mode and quantitative update from the water will be different. This requires further experimental trials.

There are various ways of using biofertilizers in aquaculture, such as feed supplement, mixing with water in the culture system and through intramuscular injection (Micheal et al., 2014). In this study, the biofertilizer was placed directly into the water to maximize its effect on all of the organisms present in the aquaponic system. It is likely that the different bacteria will influence growth differently and that the effect on fish will also depend on the response of the species. Sholihuddin et al. (2020) noticed that growth performance of Nile tilapia was better when provided with probiotic bacteria, namely, Lactobacillus sp., Bacillus sp., and Bifidobacterium sp., in the feed. These authors further observed that the combination of different strains of bacteria generated different effects on the fish growth. Obviously, several factors need to be considered especially in deciding the supplementation of diet with the single strain or mixed strains of the useful bacteria, depending on the compatibility with the stocked fish. While there was no statistically significant difference in the growth of tilapia with any of the treatments, selection of Bacillus spp. in this trial was motivated by its better performance compared to other bacterial preparations used in fish farming. Even though treatment-C have slightly higher value on SGR and DGR than treatment-B, but on a comparative basis, Bacillus spp. (Treatment-B) yielded the highest average body weight gain and total fish body weight gain (Table 1 ) but with no significant differences $(P<0.05)$ detected with other treatment. Further investigations will be necessary to examine the possibility of such incremental weight gain producing a significant difference. This could be the reason for the positive effect of Bacillus spp. in aquaculture. It is reported to improve the fish growth by enhancing its immune system and improving overall health condition, leading to a better feed uptake, nutrient assimilation, and growth (Tovar-Ramirez et al., 2004; Allameh et al., 2017). Another factor is the ability of Bacillus spp. to prohibit the colonization of harmful pathogens in the digestive tract through antibiosis process or competition for survival and stress reduction (El-Haroun et al., 2006). Absorption of nutrients in the fish alimentary canal also improves because of its detoxifying effect, hydrolysis of unwanted compounds and denaturing of undigestible components that are known to stimulate the release of enzymes which in turn enhance the digestibility and feed efficiency (Ringo et al., 2020; Romanova et al., 2020). Improvement in the feed utilization in the presence of good bacteria (Bacillus sp., Lactobacillus sp., Citrobacter sp.) in the gut of Nile tilapia was attributed to increased activities of amylase, lipase and protease by Ringo et al. (2020) who investigated the mechanisms by which these bacteria created better environmental conditions in the fish gastrointestinal tract and improved digestion and absorption of the nutrients collectively contributed to better growth.

As can be seen from Table 1 that all the observed growth parameters in Treatment-A are higher than in the Control, suggesting that the inclusion of chitosan has positively influenced the growth of GIFT. Results were obtained by Wang and Li (2011) who in addition to growth also reported flesh quality of tilapia and gut health as evident from the condition intestinal microvilli in the fish. In a detailed study on the mechanisms by which chitosan improves growth and condition of fish through digestive processes, Han et al. (2012) provided evidence of increase in the height of intestinal villi that increased the surface area for growth of microvilli for higher nutrient absorption. In a related investigation, Zaki et al. (2015) published data that highlighted the importance of gut health due to which efficient proliferation of cellular activity provides stem cells for the renewal of intestinal epithelium that is known for an active wear and tear that can happen every 3 - 4 days (Zaki et al., 2015). It deserves emphasis that chitosan dose and method of supplementation are critically important for optimizing gains in production. An excessive dose adversely affects the fish's growth and condition. Thus, Shiau and Yu (1999) observed that the chitosan amounting to $10 \%$ of feed diminished the growth of tilapia. There appear to be interspecific differences in the effect of chitosan on fish as Geng et al. (2011) noticed a supplementation of $6 \mathrm{~g} \mathrm{~kg}^{-1}$ of chitosan in cobia diet inhibited digestive hydrolysis and recommended a suitable amount of $3 \mathrm{~g} \mathrm{~kg}^{-1}$ feed for positive results. Chen and Chen (2019) suggested $5 \mathrm{mg}$ $\mathrm{kg}^{-1}$ of chitosan for a better growth performance in loach (Misgurnus anguillicadatus). These observations and other publications by Maqsood et al. (2010), Chen et al. (2014), Abd El-Naby et al. (2019) and Oushani et al. 
(2020) provide a basis for interpreting the data obtained in this study on GIFT where chitosan supported only minor gains in growth parameters due to putting this product into the culture medium in the hope of maximizing benefits for all the integrated species. In experiments where chitosan significantly enhanced growth of the fish the administration was via the feed supplementation.

Monitoring the growth of the green bean yielded interesting information which showed that the branching and formation of leaves occurred normally as was expected of a healthy plant, but fruiting did not happen. The normal healthy-looking purplish-white flowers persisted for a week and dropped off before developing into pods. Obviously, there was no water stress in aquaponics. No signs of any disease were noticed. Exposure to light was similar. The most likely reason for fruiting failure was nutrient imbalance. Green bean, like other plants, needs different nutrients during germinating, vegetating, flowering, and fruiting stages. To support growth of fish as well as plant biomass, optimizing the required nutrients and their recycling are necessary (Graber and Junge, 2009; Goddek et al., 2016). Optimizing could not be done earlier since this was never attempted in an aquaponic system before and, therefore, there was no previous information was available. The nutrient imbalance means that the composition of commercial fish feeds is according to nutritional needs of the fish, and the composition of fish faeces depends on diet composition which may not necessarily meet the requirements of the plant in the system. It is for this reason that the use of decoupled or multi-loop system that enables optimal living and growing conditions for fish, plants and microorganisms offers the solution (Eck et al., 2019). An appropriately designed aquaponic system, whether coupled or decoupled, where nutrient supply, dynamics and partitioning can be managed is a key to successful harvest. Nutrient turnover is an integral feature of aquaponics, but the success of this integrated farming is defined by the dynamic equilibrium (Somerville et al., 2014) where the nutrient concentrations are as regularly optimized as they fluctuate due to natural biological processes. An in-depth understanding of the nutrient cycles in the various sub-sections of aquaponics is vitally important for managing the whole system. It is a very biotic environment where stocked species and their roles are known but not so visible but profoundly active are the nitrifying bacteria that contribute to making the aquaponics work through water quality remediation.

The influence of weather conditions on fruiting cannot be ruled out. At the fruiting time the air temperature was above normal, in the range of $27-36$ ${ }^{\circ} \mathrm{C}$, and precipitation was naturally low. High temperature as among the adverse causes in cultivated plants has been discussed by Herbert and Herbert (2008), Nelson (2008), Yoldas and Esiyok (2009) and Hailu et al. (2017). Also, if the high temperature influenced metabolism in fish resulting in change in the nutrients in the faeces remains uncertain. It is beyond the scope of this study to examine these issues which were not anticipated when the experiment was designed. There is no published data adequate to synthesize the real reasons or cause-and-effect relations resulting in fruiting failure in the green bean.

Even though there was no pod formation in this study, the effect of application of chitosan needs to be investigated to establish its possible growth-enhancing benefits. This was consistent with the findings of Mukta et al. (2017) and Irawati (2019). Foliar application of chitosan indicated that its uptake could happen through leaves, stomata and roots (Mondal et al., 2012; Saharan et al., 2016; Mukta et al., 2017; Irawati 2019; Sathiyabama and Manikandan, 2021). Other advantages could be due to the antimicrobial activity of chitosan that prevents infection and thereby helps the plant (Orzali et al., 2017; Malerba and Cerana, 2018). Yet another advantage of chitosan application appears to be its ability to facilitate water quality remediation which is so critical for sustainable biomass production in aquaponics. As for Bacillus sp., it was chosen to be one of the ideal biofertilizers in this study because it has ability to boost the health of plants by fungicidal effect and increase the biomass production of vegetables in soilless condition (Salleh 2009; Ozdemir et al., 2016). Data provided by Pandey et al., (2018) on the use of Bacillus sp. in vegetable cultivation suggested its positive influence on the plant growth.

The data generated by the present investigation (Figure 3) is concordant with the views of Kewcharoen and Srisapoome (2019) who reported the role of Bacillus subtilis in supporting the growth and reproduction of nitrifying bacteria that lowered the concentration of ammonia after third week. Although in this study, the differences were subtle, and a lack of significant difference in all the treatments with the control could be due to small doses provided and the short culture period. These conditions need to be optimized based on extrapolation of the present findings.

The dynamics of water quality parameters in the culture system provides information of practical importance. Table 2 and Figure 4 contain data that shows reduction in concentration of $\mathrm{NH}_{3}-\mathrm{N}, \mathrm{NO}_{2}-\mathrm{N}, \mathrm{NO}_{3}-$ $\mathrm{N}$ and $\mathrm{PO}_{4}-\mathrm{P}$, improvement in dissolved oxygen and buffering of $\mathrm{pH}$ to maintain it around the neutral value.

The values of ammonia and nitrite are high, suggesting that the biofiltration by nitrifying bacteria was proceeding at a slower rate. The design optimization of aquaponic systems remains a work in progress. Investigations are ongoing to address the problem of low pressure and small surface area of aquaponic systems that will reduce the residence time of toxic nitrogenous waste should they exceed the tolerance range of the fish. Furthermore, the analysis was based on total ammonia which is the sum total of un-ionized ammonia $\left(\mathrm{NH}_{3}\right)$ which is the toxic form, and the ammonium ion $\left(\mathrm{NH}_{4}{ }^{+}\right)$. Their relative proportions in 
water depend on the $\mathrm{pH}$. In this study, $\mathrm{pH}$ was regulated and not allowed above the threshold at which the $\mathrm{NH}_{3}$ predominates. Moreover, aeration system remained active throughout to facilitate the diffusion of the gaseous form of $\mathrm{NH}_{3}$ to the air for increasing the proportion of $\mathrm{NH}_{4}^{+}$to the total ammonia concentration. In the tropical warm water conditions, the temperature fluctuations that account to spikes in nitrite were limited and were within the range of tolerance of the fish.

A higher abundance of ammonia oxidizer bacteria in water when ammonia level is $10 \mathrm{mg} / \mathrm{L}$ as reported by Suwa et al. (1994) helps in mitigating the stress. Moreover, $\mathrm{pH}$ range for inhibition of ammonia oxidizer and nitrite oxidizer bacteria is 5.8-8.5 and 6.5-8.5, below which these nitrogenous waste cause serious toxicity (Princic et al., 1998). In this experiment, the $\mathrm{pH}$ was maintained above these values. Observations of fish behaviour did not indicate any signs of ammonia toxicity which are marked by hyperactivity and convulsions initially, followed by lethargy, disorientation or decline and even loss of response to stimuli. In fact, the GIFT continued to grow for the full cycle until the completion of the experiment.

In this respect, chitosan biofertilizer (Treatment-A) was comparatively better than Treatment-C. This could be due to the capacity of chitosan as a bioadsorbent in the water (Abdel-Ghany and Salem, 2019). Research done by Bernardi et al. (2018) and Shi et al. (2020) linked this process to the many active surface areas boosted by the pore size distribution in the chitosan. Use of EM (Treatment- $\mathrm{C}$ ) reduced the concentrations of $\mathrm{NH}_{3}, \mathrm{NH}_{2}$, $\mathrm{NO}_{3}$ and $\mathrm{PO}_{4}$ when compared to the Control that indicated the ability of this product to reduce the organic substances by enhancing their decomposition, and thereby contributing to improved water quality (Kosov et al., 2017; Xu et al., 2021). Similar results were obtained by Jozwiakowski et al. (2009) on a much larger scale in a pond with an area of $1200 \mathrm{~m}^{2}$. These authors observed that that Treatment-C decreased the levels of ammonium nitrate, total nitrogen and total phosphorus more than half and improved the water quality. Talaat (2019) has attributed this role of Treatment-C microbial inoculant to its diverse types of microorganisms, including photosynthetic bacteria, lactic acid bacteria, yeast, actinomycetes and fermenting fungi which can encourage the growth of healthy plants and improve the water quality for all the species integrated in the production unit. Lananan et al. (2014) reported that components of Treatment- $C$ in this study helped in enhancing the phytoremediation by microalgae by way of phosphorus uptake and highlighted that without EM, the independent microalgae phytoremediation was not effective enough to remove ammonia and phosphorus from the wastewater. There could be other benefits of EM such as suppression of diseases (Wood et al., 1999; Kremer et al., 2001) and gain in biomass (Abd. ElMageed et al., 2020; Cui et al., 2021) but these observations are based on land-based farming systems, not the soilless system of aquaponics.
The Control set showed highest concentrations of $\mathrm{NH}_{3}, \mathrm{NH}_{2}, \mathrm{NO}_{3}$ and $\mathrm{PO}_{4}$ from the beginning of the experiment until the end. It can be deduced that the presence of the biofertilizers helped in reducing these nitrogenous compounds in the water. Treatment-B was most effective in breakdown of toxic ammonia and nitrite, and in furthering this nitrogen cycle in the system. The effectiveness of Bacillus spp. in bioremediation, especially in degradation of ammonia, nitrite and nitrate, and reducing the partial pressure of carbon dioxide has been experimentally demonstrated earlier (Soltani et al., 2019).

It is evident from all the above trials that the treatments A, B and C carried out water quality remediation, and even if the changes were not significant when observed over the period of the experimental trial, the effects are marginally positive for GIFT and the green beans. The results will probably be significant in a longer farming period.

Failure of the aquaponic system to take the green bean green beans to fruiting stage is evident from this study. It is likely that leafy vegetables and herbs thrive very well in such systems because of the lower requirement of nutrients but fruiting needs more nourishment which is required for growth of stems, leaves and flower. Those nutrients and their quantities that can support maturation and ripening of the fruit need to be examined (Bittsanszky et al., 2016; PinedaPineda et al., 2017) for maximizing the benefits of aquaponics. If pods are the nutrient-rich product for human consumption, the green bean integrated into the aquaponic system should be supported to bear fruits.

\section{Conclusions}

In aquaponics, biofertilizers can perform water quality remediation which is crucial for the well-being of all the species integrated in the production system. Low cost and accessibility of these products makes their application both economical and practical. It is a new area in the newer field of aquaponic farming system and further research will open greater potential for expanding and diversifying the scope of soilless culture with reduced ecological footprint. More investigations are needed for gaining better insights into the nutrient cycling in aquaponics based on different species of fish or invertebrates of aquaculture importance and plants. Specifically, data is required on dynamics of turnover of each macronutrient, its formation and transformation, and its uptake for biomass gains, and the influence of integrated species on each other as well as on the water quality. Also, worth exploring is the interaction of biofertilizers with the nitrifying bacteria that invariably settle in the system to consume ammonia released as a metabolic waste by the fish. Of special interest will be the detailed understanding of the possible synergistic role of the nitrifying bacteria and the $B C L$ and $E M$ introduced into the system. An important issue identified in this study is the failure of fruiting of green 
beans. Nevertheless, this finding has shown what needs to be done to address this problem by way of controlling environmental conditions and experimental verification of the need for incorporating the fruiting supplements in biofertilizers. These results will contribute to bridging the knowledge gaps on the role of the various products tested in this study for better results from aquaponic systems.

\section{Ethical Statement}

The procedures described in this experiment were carried out in complete compliance with UMS norms and regulations governing the Care and Use of Animals for Scientific Purposes, as set forth by the UMS Animal Ethics Committee. All acknowledged ethical and professional behaviour principles were followed

\section{Funding Information}

This study was financially supported by Niche Research Grant Scheme of the Ministry of Higher Education Malaysia (MOHE) with grant code NRGSO001.

\section{Author Contribution}

Syafiqah: Material preparation, investigating, data collecting, analysis and writing - original draft, Abentin Estim: data interpretation, provided assistance with water quality analysis, data curation, resources, Sitti Raehanah: project administration, assisted in the interpretation of biofertilizers role, conceptualization, resources, Saleem Mustafa: supervision, validation, writing - review \& editing the manuscript and polished the content after looking over the data analysis

\section{Conflict of Interest}

All the authors declare that they have no known competing financial or non-financial, professional, or personal conflicts that could have appeared to influence the work reported in this paper.

\section{Acknowledgements}

Special thanks dedicated to the Department of Fisheries, Marakau, Ranau, Sabah for supplying GIFT for this experiment and special gratitude for the technical and support of Borneo Marine Research Institute for providing experimental area for this study

\section{References}

Abd El-Mageed, T.A., Rady, M.M., Taha, R.S., Abd El Azeam, S. (2020). Effects of integrated use of residual sulfurenhanced biochar with effective microorganisms on soil properties, pant growth and short-term productivity of Capsicum annuum under salt stress. Scientia Horticulturae, 261: 108930.
Abd El-Naby, F.S., Naiel, M.A.E., Al-Sagheer, A.A., Negm, S.S. (2019). Dietary chitosan nanoparticlas enhance the growth, production performance, and immunity in Oreochromis niloticus. Aquaculture, 501: 82 - 89.

Abdel-Ghany, H.M. and Salem, M.E.S. (2019). Effects of dietary chitosan supplementation on farmed fish; a review. Reviews in Aquaculture, 1-15, doi:10.1111/raq.12326.

Allameh, S.K., Noaman, V. and Nahavandi, R. (2017). Effects of probiotic bacteria on fish performance. Review article on Advanced Techniques in Clinical Microbiolgy, 1:2

Atieno, M., Herrmann, L., Nguyen, H. T., Phan, H. T., Nguyen, N. K., Srean, P., Zhiyong, R., Tittabutr, P., Shutsrirung, A., Brau, L. and Didier L. (2020). Assessment of biofertilizer use for sustainable agriculture in the Great Mekong River. Journal of Environmental Management, 275: 111300.

Bernardi, F., Zadinelo, I. V., Alves, H. J., Meurer, F. (2018). Chitins and chitosan for the removal of total ammonia of aquaculture effluents. Aquaculture 483, $203-212$.

Bittsanzky, A., Uszinger, N., Gyulai, G., Mathis, A., Junge, R., Villaroel, M., Kotzen, B. and Komives, T. (2016). Nutrient supply of plants in aquaponic systems. Ecocycles, 2(2): 17-20.

Cerozi, B.D.S. and Fitzsimmons, K. (2016). Use of Bacillus spp. to enhance phosphorus availability and serve as a plant growth promoter in aquaponics systems. Scientia Horticulture, 211: $277-282$.

Chen, J and Chen, L. (2019). Effects of chitosan-supplemented diets on the growth performance, nonspecific immunity and health of loach fish (Misgurnus anguillicadatus). Carbohydrate Polymers, 225, 115227.

Chen, Y., Zhu, X., yang, Y., Han, D., Jin, J, and Xie, S. (2014). Effect of dietary chitosan on growth performance, haematology, immune response, intestine microbiota and disease resistance in gibel carp (Carassius auratus gibelio). Aquaculture nutrition, 20: $532-546$.

Cui, Q., Xia, J., Yang, H., Liu, J. and Shao, P. (2021). Biochar and effective microorganisms promote Sesbania cannabina growth and soil quality in the coastal saline-alkali soil of the Yellow River Delta, China. Science of the Total Environment, 756: 143801.

Eck M., Körner O., Jijakli M.H. (2019). Nutrient Cycling in Aquaponics Systems. In: Goddek S., Joyce A., Kotzen B., Burnell G.M. (Eds) Aquaponics Food Production Systems. Springer, Cham.

Endut, A., Jusoh, A. and Wan Nik, W.B. (2010). Nutrient removal from aquaculture wastewater by vegetable production in aquaponics recirculation system. Desalination and Water Treatment, 32: 422-430.

El-Haroun, E.R., Goda, A.M.A. and Chowdhury, M.A.K. (2006). Effect of dietary probiotic Biogen supplementation as a growth promoter on growth performance and feed utilization of Nile Tilapia Oreochromis niloticus (L.). Aquaculture research, 37(14): $1473-1480$.

Estim, A., Saufie, S. and Mustafa S. (2019). Water quality remediation using aquaponics sub-systems as biological and mechanical filters in aquaculture. Journal of Water Processing, 30, 100566. http//doi.org/10.1016/j.jwpe.2018.02.001

Geng, X., Dong, X., Tan, B., Yang, Q., Chi, S., Liu, H. and Liu X. (2011). Effects of dietary chitosan and Bacillus subtilis on the growth performance, non-specific immunity and disease resistance of cobia, Rachycentron canadum. Fish \& Shellfish Immunology, 31: $400-406$.

Goddek S, Schmautz Z, Scott B, Delaide B, Keesman K, Wuertz 
S, Junge R. (2016). The effect of anaerobic and aerobic fish sludge supernatant on hydroponic lettuce. Agronomy 6:37.

Graber A, Junge R. (2009). Aquaponic systems: nutrient recycling from fish wastewater by vegetable production. Desalination 246:147-156.

Hailu, N., Fininsa, C., Tana, T. and Mamo, G. (2017). Effects of temperature and moisture on growth of common bean and its resistance reaction against common bacterial blight (Xanthomonas axonopodis pv. Phaseoli strains). Journal of Plant Pathology \& Microbiology, 8:9, doi:10.4172/2157-7471.1000419.

Han, X., Du, W., Huang, Q., Xu, Z. and Wang, Y. (2012). Changes in small intestinal morphology and digestive enzyme activity with oral administration of copper-loaded chitosan nanoparticles in rats. Biol Trace Emem Res, 145 $355-360$.

Herbert, H. and Herbert S. (2008). Aquaponics in Australia: The integration of aquaculture and hydroponics, aquaponics Pty Ltd., Australia, pp. $81-100$.

Irawati, E.B. (2019). Application of chitosan for vegetative growth of kemiri sunan plant in marginal land. IOP Conference Series: Earth and Environmental Science, 250, 012089.

Javaid, A. Effects of biofertilizers combined with different soil amendments on potted rice plants. (2011). Chilean Journal of Agricultural Research, 71(1): $157-163$.

Javaid, A. and bajwa, R. (2011). Effect of effective microorganism application on crop growth, yield, and nutrition in Vigna radiata (L.) wilczek in different soil amendments systems. Communications in Soil Science and Plant Analysis, 42: $2112-2121$.

Jozwiakowski, K., Czernas, K. and Szczurowska, A. (2009). Preliminary results of studies on the purification of water in a pond using the SCD probiotics technology. Ecohydrology \& Hydrobiology, 2-4: 307-312.

Kazosi, N., Tandlich, R., Fick, M., Kiaser, H. and Wilhelmi, B. (2019). Iron supplementation and management in aquaponic systems: A review. Aquaculture Reports, 100221.

Kewcharoen, W. and Srisapoome P. (2019). Probiotic effects of Bacillus spp. from pacific white shrimp (Litopenaeus vannamei) on water quality and shrimp growth, immune response, and resistance to Vibrio parahaemolyticus (AHPND strains). Fish and Shellfish Immunology, 94: 175 $-189$.

Kosov, S., Shirahama, K., Li, C. and Grzegorzek, M. (2017). Environmental microorganism classification using conditional random fields and deep convolution neural networks, Pattern Recognition. http//doi.org/10.1016/j.patcog.2017.12.021

Kremer, R.J., Ervin, E.H., Wood, M.T. and Abuchar, D. (2001). Control of Sclerotinia homoeocarpa in turfgrass using effective microorganism. Retrieved from, https://www.reaearchgate.net/publication/242224354

Lananan, F., Abd Hamid, S.H., Din, W.N.S., Ali, N., Khatoon, H., Jusoh, A. and Endut, A. (2014). Symbiotic bioremediation of aquaculture wastewater in reducing ammonia and phosphorus utilizing Effective Microorganism (EM-1) and microalgae (Chlorella sp.). International Biodeterioration \& Biodegradation, retrieved from htttp://dx.doi.org/10.1016/j.ibiod.2014.06.013.

Malerba, M and Cerana, R. (2018). Recent advances of chitosan applications in plants. Polymers, 10: 118.

Malusa, E. and Vassilev N. (2014). A contribution to start a legal framework for biofertilizers. Applied Microbiology and Biotechnology, 98 (15): 6599 - 6607.

Maqsood, S., Singh, P., Samoon, M.H. and Balange, A.K. (2010). Effect of dietary chitosan on non-specific immune response and growth of Cyprinus carpio challenged with Aeromonas hydrophila. International Aquatic Research, 2: $77-85$.

Menendez E. and Garcia-Fraile P. (2017). Plant probiotic bacteria: solutions to feed the world. Review: AIMS Microbiology, 3(3): 502-524.

Micheal, E.T., Amos, S.O. and Hussaini, L.T. (2014). A review on probiotics application in aquaculture. Fisheries and Aquaculture Journal, 5(4).

Mondal, M.M.A., Malek, M.A., Puteh, A.B., Ismail, M.R., Ashrafuzzaman, M.A., Naher, L. (2012). Effect of foliar application of chitosan on growth and yield in okra. Australian Journal of Crop Science, 6(5): 918 - 921.

Mukta, J.A., Rahman, M., As Sabir, A., Gupta, D.R., Surovy, M.Z., Rahman, M. and Islam, M.T. (2017). Chitosan and plant probiotics application enhance growth and yield of strawberry. Biocatalysis and Agricultural Biotechnology, 11: 9-18.

Nelson, L.N. (2008). Aquaponic food production: Raising fish and plants for food and profit. Nelson and Pade, Inc., United States of America, pp. $122-132$.

Nikitin, A.N., Cheshyk, I.A., Gutseva, G.Z., Tankevich, E.A., Shintani, M. and Okumoto, S. (2018). Impact of effective microorganisms on the transfer of radioactive cesium into lettuce and barley biomass. Journal of Environmental Radioactivity, 192: $491-497$.

Omar, W.A., Abdel-Salam, R.G., Mahmoud, H.M. (2017). The use of Effective Microorganisms (EM) as a probiotic on cultured Nile tilapia, Oreochromis niloticus. Egypt. J. Zool., In press retrieved from https://www.researchgate.net/publication/319187434.

Orzali, L., Corsi, B., Forni, C. and Riccioni, L. (2017). Chitosan in agriculture: A new challenge for managing plant disease. Biological Activities and Application of Marine Polysaccharides, http://dx.doi.org/10.5772/66840.

Oushani, A.K., Soltani, M., Sheikhzadeh, N., Mehrgan, M.S., Islami, H.R. (2020). Effects of dietary chitosan and nanochitosan loaded clinoptilolite and immune responses of rainbow trout (Oncorhynchus mykiss). Fish and Shellfish Immunology, 98: 210-217.

Ozdemir, Y., Polat, Z., Ozkan, M. and Kosti, R.I. (2016). Effects of selected bio-fungicide and fungicide treatments on shelf life and quality characteristics of romaine lettuce (Lactuca sativa L.). Journal of Food Quality, 39: 25-35.

Pandey, C., Bajpai, V.K., Negi, Y.K., Rather, I. and Maheshwari, D.K. (2018). Effect of plant growth promoting Bacillus spp. on nutritional properties of Amaranthus hypochondriacus grains. Saudi Journal of Biological Sciences, 25: 1066-1071.

Pineda-Pineda, J., Miranda-Velazquez, I., Rodriguez-Perez, J.E., Ramirez-Arias, J.A., Perez-Gomez, E.A., Garcia-Antonio, I.N., Morales-Parada, J.J. (2017). Nutrimental balance in aquaponic lettuce production. Acta Horticulturae, doi:10.17660/ActaHortic.2017.1170.141.

Ramasamy, M., Geetha, T. and Yuvaraj, M. (2020). Role of biofertilizers in plant growth and soil health. IntechOpen, doi:http://dx.doi.org/10.5772/intechopen.87429.

Ringo, E., Doan, H.V., Lee, S.H., Soltani, M., Hoseinifar, S.H., Harikrishnan, R. and Song, S.K. (2020). Probiotic, lactic acid bacteria and bacilli: interesting supplementation for aquaculture, Journal of Applied Microbiology, 129: 116- 
136

Romanova, E., Spirina, E., Romanov, V., Lyubomirova, V. and Shadyeva, L. (2020). Effects of Bacillus subtilis and Bacillus licheniformis on catfish in industrial aquaculture. E3S Web Conf. XIII International Scientific and Practical Conference 'State and Prospects for the Development of Agribusiness, 175. https://doi.org/10.1051/e3sconf/202017502013

Roosta, H.R. and Hamidpour, M. (2011). Effects of foliar application of some macro- and micro-nutrients on tomato plants in aquaponic and hydroponic systems. Scientia Horticulturae, 129(3): 396 - 402.

Saharan, V., Kumaraswamy, R.V., Choudry, R.C., Kumari, S. Pal, A., Raliya, R. and Biswas, P. (2016). Cu-chitosan nanoparticles mediated sustainable approach to enhance seedling growth in maize by mobilizing reserved food. Journal of agricultural and food chemistry, 64(31): $6148-6155$

Salleh, S.A. (2009). Precision stressing by supplemental Ca and Bacillus subtilis FZB24 to improve quality of lettuce under protected cultivation, Acta Horticulturae, 824: 297-302.

Sathiyabama, M. and Manikandan, A. (2021). Foliar application of chitosan nanoparticles improves yield, mineral content and boost innate immunity in finer millet plants. Carbohydrate Polymers, 258: 117691.

Saufie, S., Estim, A., Shalleh, S.R., Mustafa, S. (2020). Production efficiency of green beans integrated with tilapia in a circular farming system of media-filled aquaponics. Spanish Journal of Agricultural Research, 18 (3), e0611. https://doi.org/10.5424/sjar/2020183-16038

Shi, Y., Hu, H. and Ren H. (2020). Dissolved organic matter (DOM) removal from biotreated coking wastewater by chitosan-modified biochar: Adsorption fractions and mechanisms. Bioresource Technology, 122281.

Shiau, S. and Yu, Y. (1999). Dietary supplementation of chitin and chitosan depresses growth in tilapia, Oreochromis niloticus $\times$ O. aureus. Aquaculture, 1-4: 439-446.

Sholihuddin, T.D., Arief, M. and Kenconojati, H. Effect of different bacterial strain in probiotics on the growth performance of Nile Tilapia (Oreochromis niloticus). (2020). IOP Conference Series: Earth and Environmental Science, 441. Doi:10.1088/1755-1315/441/1/012072.

Soltani, M., Ghosh, K., Hoseinifar, S.H., Kumar, V., Lymbery, A.J. and Ringo, E. (2019). Genus bacillus, promising probiotics in aquaculture: Aquatic animal origin, bioactive components, bioremediation and efficacy in fish and shellfish. Reviews in Fisheries Science \& Aquaculture. https://doi.org/10.1080/23308249.2019.1597010

Somerville C, Stankus A, Lovatelli A. (2014). Small-scale aquaponic food production. Integrated fish and plant farming. Food and Agriculture Organisation of the United Nations, Rome.

Sun, B., Gu, L., Bao, L., Zhang, S., Wei, Y., Bai, Z, Zhuang, G. and Zhuang, X. (2020). Application of biofertilizer containing Bacillus subtilis reduced the nitrogen loss in agricultural soil. Soil Biology and Biochemistry, 148: 107911.

Talaat, N.B. (2019). Effective microorganisms: An innovative tool for inducing common bean (Phaseolus vulgaris $\mathrm{L}$.) salt-tolerance by regulating photosynthetic rate and endogenous phytohormones production. Scientia Horticulturae, 250: $254-264$.

Thiam, S., Fall, J., Loum, A., Sagne, M. and Diouf, M. (2015). Use of Effective Microorganisms (EM) in tilapia diets: effects of growth performance and carcass composition. International Journal of Current Microbiology and Applied Sciences, 4 (11): 536 - 549.

Tovar-Ramirez, D., Infante, J.Z., Gatesoupe, F.J. and VazquezJuarez, R. (2004). Influence of dietary live yeast on European sea bass (Dicentrarchus labrax) larval development. Aquaculture, 234 (1-4): 415-427.

Trang, N.T.D. and Brix, H. (2014). Use of planted biofilters in integrated recirculating aquaculture-hydroponics systems in the Mekong Delta, Vietnam. Aquaculture Research, 45: $460-469$.

Umesha, S., Singh, P.K. and Singh R.P. (2018). Chapter 6 Microbial biotechnology and sustainable agriculture. Biotechnology for Sustainable Agriculture, 185 - 205, doi org/10.1016/B978-0-12-812160-.00006-4

Wang, M., Zheng, Q., Shen, Q and Guo, S. (2013). The critical role of potassium in plant stress response. International Journal of Molecular Sciences, 14: 7370 - 7390.

Wang, Y. and Li J. (2011). Effects of chitosan nanoparticles on survival, growth, and meat quality of tilapia, Oreochromis nilotica. Nanotoxicology, 5(3): $425-431$.

Wood, M.T., Miles, R. and Tabora, P. (1999). EM-fermented plant extract and EM5 for controlling pickleworm (Diaphania nitidalis) in organic cucumbers. IFOAM Tholey-Theley Germany. Organic agriculture - the incredible solution for $21^{\text {st }}$ century. Proceedings of the $12^{\text {th }}$ International IFOAM Scientific Conference, Mar del Plata, Argentina, November 15-19. URL https://www.infrc.or.jp/knf/PDF\%20KNF\%20Conf\%20D ata/C5-7-185.pdf

Xu, W., Mawolo, P.Y., Gao, J., Chu, L., Wang, Y., Nie, Z., Song, L., Shao, N., Gao, J., Xu, P. and Xu, G. (2021). Effects of supplemental Effective Microorganisms in feed on the growth, immunity, and appetite regulation in juvenile GIFT tilapia. Aquaculture Reports, 19 http//doi.org/10.1016/j.aqrep.2020.100577.

Yang, T. and Kim, H. (2020). Characterizing nutrient composition and concentration in tomato-, basil-, and lettuce-based aquaponic and hydroponic systems. Water, 12(5), 1259; doi.org/10.3390/w12051259.

Yoldas, F. and Esiyok, D. (2009). The influence of temperature on growth and yield of green beans for processing. International Journal of Agricultural Research, 4(3): 124 130.

Zhang, Li, Y., Zhang, F., Li, Y. and Zeng, R. J. (2020). Two-stage enrichment of hydrogen-oxidizing bacteria as biofertilizers. Chemosphere. https://doi.org/10.1016/j.chemosphere.2020.128932

Zaki, M.A., Salem, M. El-S., Gaber, M.M. and Nour, A.M. (2015). Effect of chitosan supplemented diet on survival, growth, feed utilization, body composition \& histology of sea bass (Dicentrarcus labrax). World Journal of Engineering and technology, 38-47. 